\title{
Lereno Selinuntino e Glauceste Satúrnio: presença de lirismo pastoril e alvinegro no Arcadismo luso-brasileiro
}

Tânia de Assis Silva

\author{
Universidade Estadual Paulista "Júlio de Mesquita Filho"
}

\begin{abstract}
Resumo
Neste artigo, propõe-se a leitura comparativa entre alguns poemas de Domingos Caldas Barbosa, o pastor Lereno Selinuntino, e de Cláudio Manuel da Costa, de nome pastoril Glauceste Satúrnio, considerando que ambos pertenceram ao movimento literário do Arcadismo e quanto à estética, à temática e à erudição na voz os poetas pastores se assemelham quando deixam vazar o lirismo amoroso usando elementos bucólicos, característicos da poética árcade; entretanto, além da voz poética arcádica de Lereno, considera-se a voz que assume sua identidade negra e se distingue dos poetas árcades pela inovação no fazer poético marcado na fluidez do lirismo que passa a ser vazado na voz afro-brasileira, cantando a modinha e o lundu, ao trazerem expressões tanto da linguagem popular brasileira quanto marcas da oralidade africana.
\end{abstract}

Palavras-chave: poesia árcade; Lereno; Glauceste; bucolismo; voz afro-brasileira.

\begin{abstract}
This article proposes a comparative reading between some poems by Domingos Caldas Barbosa, pastor Lereno Selinuntino, and Cláudio Manuel da Costa, pastoral name Glauceste Satúrnio, considering that the two poets belonged to the Neoclassicism and the aesthetics, thematic and erudition in the voice, the pastoral poets are especially similar when they let love lyrism leak using bucolic elements, characteristic of Arcadian poetics, but in addition to Lereno's arcadic poetic voice, one must also consider the voice that assumes its black identity and is distinguished from the arcadian poets for innovation in his poetic making marked by fluidity of lyricism that is also characterized in the Afro-Brazilian voice singing the modinha and lundu that bring expressions of Brazilian popular language and marks of African orality.
\end{abstract}

Keywords: arcadian poetry; Lereno; Glauceste; bucolism; Afro-Brazilian voice. 
Verdes campos, fonte fria, Fundo vale, altos rochedos, De quem amantes segredos Lereno aflito confia. Barbosa (1798, p. 24)

Uma leitura superficial e despretensiosa dos versos da primeira estrofe do poema "Retratos da minha linda pastora", transcrito na epígrafe, pode evocar os versos de Cláudio Manuel da Costa tanto no estilo de herança camoniana dos sonetos e redondilhas que remetem à forma neoclássica dos poemas do árcade mineiro, quanto à imagem pastoril idealizada pelos elementos bucólicos como "verdes campos, fonte fria", "Fundo vale, altos rochedos", dos quais os poetas árcades se valiam para cantar o lirismo nos seus poemas, especialmente Cláudio Manuel da Costa ao versejar sobre os valores de sua terra natal, Minas Gerais, se vale dos elementos como "natureza", "penhascos" e "entre penhas" descrevendo "o berço em que nasci”, seu lugar de origem, no segundo verso da primeira estrofe do "Soneto XCVIII". No entanto, no último verso da primeira estrofe do poema, de Domingos Caldas Barbosa, ou simplesmente Caldas Barbosa como assim preferem se referir ao poeta os autores críticos Antonio Candido (2009), Luís da Câmara Cascudo (1958) e José Ramos Tinhorão (2004), o poeta se identifica pelo nome pastoril arcádico Lereno Selinuntino da mesma forma que se assumiam pastores todos os poetas árcades e aqui se destaca Glauceste Satúrnio, nome árcade do poeta pastor Cláudio Manuel da Costa (1729-1789), contemporâneo de Domingos Caldas Barbosa (1740-1800).

Neste estudo comparativo de Domingos Caldas Barbosa a justificativa de destaque, dentre os poetas árcades, ao poeta Cláudio Manuel da Costa se dá com base nas declarações do crítico Candido (2009) quando afirma que "os ideais neoclássicos só se realizaram, quanto aos escritores brasileiros, nos da geração seguinte à dos fundadores da Arcádia lusitana, dos quais receberam, polidos e afinados, os instrumentos literários" e que foi "à influência direta de Cláudio Manuel da Costa, que os estimulou sem dúvida no caminho da poesia" (CANDIDO, 2009, p. 113).

\section{Lereno e Glauceste: semelhança pastoril}

Ao considerar os nomes arcádicos e as semelhanças que envolvem as características pastoris dos poetas em estudo, é imprescindível refletir nas palavras de Candido (2009), que sobre a denominação de Arcádia traz a seguinte explicação:

Escolhendo a designação de Arcádia lusitana para o seu grêmio, os reformadores da literatura portuguesa se conformavam ao exemplo italiano; ao cultivarem o gênero bucólico, ou adotarem nomenclatura bucólica nos seus poemas, integravam-se numa corrente, também de inspiração italiana imediata, mas de boas, excelentes raízes portuguesas; corrente que parecia a própria condição de um movimento cujo escopo era restabelecer a simplicidade e desbaratar a joalheria falsa do Cultismo decadente (CANDIDO, 2009, p. 62). 
Quanto ao nome pastoril adotado por cada um dos poetas pertencentes à Arcádia, Candido (2009) manifesta a elucidação a seguir:

No Arcadismo, além das diferentes formas assumidas pelo mito da idade de ouro, e consequente exaltação da vida campestre, esta disposição do espírito se manifesta na diminuição de escala do sentimento amoroso, tratado com maior humildade ou, quando não, simplicidade mais acentuada. A poesia bucólica se caracteriza por uma delegação poética, a saber, a transferência da iniciativa lírica a um pastor fictício (CANDIDO, 2009, p. 63).

São poucos os poemas em que Cláudio Manuel da Costa os assina com seu nome pastoril, Glauceste Satúrnio, porém há um pronunciamento, confirmando a existência da Arcádia Ultramarina em Minas na data de $1768,{ }^{1}$ em O parnaso obsequioso e obras poéticas sob a organização de Proença Filho (1996), em que o poeta assim se autointitula enquanto descreve a Arcádia e a atividade de outros pastores;

Parece que já reclinados sobre a relva se deixam ver os nossos músicos Pastores! As faias mais copadas, os álamos, os pinhos frondosos tecem vegetantes dosséis com que da calma se defendem; vagam sem temor pelos campos os esparzidos rebanhos; as feras não os perseguem, divertidos, entretanto toma Orisênio a frauta para cantar o seu Daliso; Glauceste uma inscrição lhe prepara ao nome; mimosas e sinceras Ninfas tecem coroas de flores para a formosa Lucinda; tudo respira delícia, tudo prazer (PROENÇA FILHO, 1996, p. 341).

Já Domingos Caldas Barbosa assume o nome árcade pastoril em muitos dos seus poemas, além de em Retratos da minha linda pastora, na obra Viola de Lereno. A estudiosa Sawaya (2015, p. 25-26) assim afirma, sobre inscrição no soneto de abertura do Almanak das Musas (1793), "deixando de lado a sua modéstia e provavelmente para valorizar esta obra, Caldas Barbosa empresta a sua chancela mais relevante e assina: "Lereno Selinuntino, da Arcádia de Roma"”. Endossando a afirmação, a estudiosa declara que o "autor do mais recente e completo estudo sobre Domingos Caldas Barbosa, José Ramos Tinhorão, inclui inúmeras novas informações baseadas em intensa pesquisa de fontes primárias” (SAWAYA, 2015, p. 15). E Tinhorão (2004) assim confirma as informações quanto ao nome pastoril arcádico de Domingos Caldas Barbosa:

\footnotetext{
“A existência de uma Academia em Minas em 1768 está clara neste pronunciamento; sua conformação arcádica é visível nas linhas que se seguem. [...] Recentemente Antonio Candido divulgou um documento assinado pelo Custódio da Arcádia Romana, Mireo Rofeático, que dá notícia de uma Colonia Oltramarina. Trata-se de um diploma conferido ao poeta brasileiro Joaquim Inácio de Seixas Brandão, de nome pastoril Driásio Erimanteu, em 1764. Esta Arcádia Ultramarina, ou Colônia Ultramarina, estaria ligada à Arcádia Romana e teria sido criada por empenho de Basílio da Gama, ou Termindo Sipílio, membro comprovado, como se sabe, da Arcádia Romana" (CANDIDO, 1993, p. 130-137).
} 
futuro autor da Viola de Lereno revelava ter gravado no tronco de um cedro existente junto à fonte, por aquela década de 1760, "o nome de Lereno" - "que é nome, que me foi na Árcádia dado": "Cuido que inda conserva erguido Cedro/O nome de Lereno ali gravado". Ora, como esse nome arcádico de Lereno só aparece ligado a Domingos Caldas Barbosa na assinatura de composições incluídas no Almanaque das Musas, em 1793 (como na "Carta Segunda a Arminda", à p. 8, onde se lê: "Por Lereno Selinuntino da Arcádia de Roma, aliás D. C. B.), pode-se concluir que desde aqueles seus tempos de juventude em Coimbra o poeta já se identificava com a figura literária que tal nome recobria (TINHORÃO, 2004, p. 49).

O estudioso caracteriza como coerente a escolha do nome arcádico de Domingos Caldas Barbosa e afirma ainda que esta coerência se deve ao fato de que

Lereno era como na virada dos séculos XVI-XVII se denominava poeticamente enquanto pastor, em suas éclogas, o poeta Francisco Rodrigues Lobo (c. 1580-1622). E a coerência estava em que - tal como agradava ao brasileiro Caldas Barbosa fazer no século XVIII em suas cantigas - fora Rodrigues Lobo quem em suas Églogas, de 1605, fizera reviver o emprego das redondilhas da velha tradição portuguesa vinda do Cancioneiro Geral (TINHORÃO, 2004, p. 49).

Em vários dos poemas é possível perceber que é nítida a aproximação no estilo poético árcade dos poetas pastores Lereno e Glauceste, tanto por cantarem à musa Nize para Lereno no poema "Retrato de Nize" e Nise para Glauceste no "Soneto XIII", quanto pela visível presença de elementos marcadamente bucólicos quando o eu lírico dá vazão aos mais diferentes sentimentos.

\section{Retrato de Nize}

Nize formosa

Quem te não vê,

Não sabe ainda

Beleza o que é

Não há beleza

Como a que tens

Pastoras lindas

Há, qu'eu bem sei,

Mas quem te iguale

Nunca eu achei

Não etc.

Louro cabelo

N'outras se vê

E o teu tem mais

Um não sei que

Não etc. [...]

(BARBOSA, 1944, p. 114). 
Nise? Nise? Onde estás? Aonde espera

Achar-te uma alma que por ti suspira,

Se quanto a vista se dilata, gira,

Tanto mais de encontrar-te desespera!

Ah, se ao menos teu nome ouvir pudera

Entre esta aura suave, que respira!

Nise, cuido que diz; mas é mentira.

Nise, cuidei que ouvia; e tal não era.

Grutas, troncos, penhascos da espessura,

Se o meu bem, se a minha alma em vós esconde,

Mostrai, mostrai-me a sua formosura.

Nem ao menos o eco me responde!

Ah, como é certa a minha desventura!

Nise? Nise? Onde estás? Aonde? Aonde?

(PROENÇA FILHO, 1996, p. 56).

Quanto à forma, Lereno remete a Glauceste apenas as estrofes em quadra evocando as primeiras estrofes do soneto, porém já não se prende ao molde decassílabo dos versos que Glauceste conserva do estilo camoniano; no entanto, os dois pastores extravasam o lirismo louvando a formosura de suas musas. Para Lereno, o eu lírico é arrebatado pela beleza, de "Nize formosa", inigualável da pastora que tem mais "Um não sei que" do que as lindas pastoras convencionais de louros cabelos, musas inspiradoras de outros poetas árcades, e tal encantamento perdura por todo o poema dando perfeição à beleza do retrato poético ao passo que Glauceste se vale de elementos da natureza para quem suspira, desespera, clama para "Grutas, troncos, penhascos da espessura", que lhe mostre a formosura escondida, inacessível de sua musa, "Mostrai, mostrai-me a sua formosura", o que é motivo de desventura do pastor diante da ausência e do silêncio da pastora.

Despedida

Escuta ó vale

Suspiros meus

Vê que eu te digo

Adeus, adeus.

Do roto seio

Dos montes teus,

Repita o eco

Adeus, adeus.

As mãos, e os olhos 
Erguendo aos Céus,

Saudoso exclamo

Adeus, adeus.

Tu viste um dia

Prazeres meus,

Já se acabaram

Adeus, adeus.

[...]

(BARBOSA, 1944, p. 72-74).

\section{Soneto VIII}

Este é o rio, a montanha é esta,

Estes os troncos, estes os rochedos;

São estes inda os mesmos arvoredos,

Esta é a mesma rústica floresta.

Tudo cheio de horror se manifesta,

Rio, montanha, troncos e penedos,

Que de amor nos suavíssimos enredos

Foi cena alegre, e urna é já funesta.

Oh, quão lembrado estou de haver subido

Aquele monte, e as vezes que baixando

Deixei do pranto o vale umedecido!

Tudo me está a memória retratando,

Que da mesma saudade o infame ruído

Vem as mortas espécies despertando

(PROENÇA FILHO, 1996, p. 54).

Ao comparar os poemas "Despedida" de Domingos Caldas Barbosa e o "Soneto VIII" de Cláudio Manuel da Costa, o lirismo extravasa suspiros em Lereno (v. 2, primeira estrofe) e o pranto em Glauceste (v. 3, terceira estrofe) evocando o vale, o(s) monte(s) e a montanha para fazer ser ouvido o ruído da saudade em Cláudio Manuel da Costa (v. 2, última estrofe) da mesma forma que Domingos Caldas Barbosa quer fazer ser ouvidos seus suspiros de saudade (v. 1 e 2, primeira estrofe).

Quanto à comparação dos ideais neoclássicos caracterizando cada poeta árcade, Candido (2009), que já havia destacado Cláudio Manuel da Costa como o poeta que "estimulou" os contemporâneos "no caminho da poesia", assim caracteriza Domingos Caldas Barbosa.

Caldas Barbosa empresta categoria literária à modinha. São traços importantes para completar a expressão da nova sensibilidade, amaciando, colorindo, adoçando o estilo regular e lógico do Classicismo. Junto ao legado harmônico da Arcádia e às suas nobres cadências prepara-se deste modo uma invasão de melodia que habituará o ouvido à melopeia, facilitando, desintelectualizando a percepção lírica (CANDIDO, 2009, p. 113). 


\section{Inovação em Lereno, igualdade com Glauceste?}

Ao mesmo tempo que Candido (2009) reconhece a inovação no estilo poético de Domingos Caldas Barbosa, põe em dúvida a autenticidade do versejar inovador do poeta como pertencente ao mesmo lugar de igualdade entre seus contemporâneos, que se mantinham conservadores quanto à tradição, quando assim se refere a Lereno: "Caldas Barbosa, como ele mestiço, músico, terno e amaneirado, foi um simples modinheiro sem relevo criador". Dando continuidade a esta afirmação, o crítico reitera:

No entanto, deve ser posto na mesma chave, porque a sua obra chega à consequência extrema de certas tendências melódicas e concepcionais da Arcádia, que em Glaura já tocam o ponto onde a poesia se desfaz na música. Metastasio, que passou a vida escrevendo para ser musicado, acentuava que o verso é o elemento diretor no consórcio entre ambas; no limite, porém, a palavra se tornava mero pretexto para o banho sonoro que deveria provocar a emoção, como vemos em Caldas Barbosa (CANDIDO, 2009, p. 154).

Apesar de usar a expressão "deve ser posto na mesma chave" comparando Domingos Caldas Barbosa aos poetas árcades, Candido (2009) corrobora com a dúvida que dá a entender, ao leitor, quanto ao lugar de igualdade ou inferioridade do poeta no que se refere à inovação do estilo poético do pastor Lereno. Em outro trecho o crítico assim fala sobre o fazer poético de Domingos Caldas Barbosa:

Entregues à leitura, inexistem, como acontece quase sempre às letras de modinhas, que Caldas teve contudo o mérito de dignificar e que influiria ponderavelmente na evolução rítmica do verso português. Mas embora haja contribuído, pois, para o adensamento daquela atmosfera encantadora e frívola de melodias fugitivas que embalaram o Rococó lisboeta, o fato é que, visto de hoje, o "trovista Caldas", tão simpático e boa pessoa, tão maltratado por Bocage, desaparece praticamente ao lado dos patrícios mais bem dotados (CANDIDO, 2009, p. 156).

Diante desta afirmação a dúvida se acentua e surgem os seguintes questionamentos: Em que sentido o poeta "desaparece"? Em relação a quais aspectos são os "patrícios mais bem dotados" que Domingos Caldas Barbosa? Indagações que encontram acolhimento no questionamento do crítico Cascudo (1958, p. 29) quando inquire: "O poeta Caldas Barbosa fica na classe dos 'Poetas Menores'?” Ao que o crítico esclarece:

Caldas Barbosa tem dois aspectos "maiores" para valorizá-lo. Primeiro, seus versos continuam vivos e de contagiante simplicidade quando as obras maciças foram recolhidas, aos pedaços, aos museus das antologias arcaicas. [...] Segundo, o poeta é também um documento inarredável e obstinado da fidelidade brasileira na Côrte de Portugal quando éramos Vice-Reino. A "vulgaridade", "banalidade", "mediocridade", 
"rasteirice" da Viola de Lereno saíram, direta e autenticamente, em alta percentagem, da memória, do espírito, da ternura coletiva do Brasil. Foi, na espécie, a primeira amostra de matéria-prima que exportamos para Portugal (CASCUDO, 1958, p. 29-30).

Se a declaração a que Candido (2009) se refere "aos patrícios mais bem dotados", colocando Domingos Caldas Barbosa em lugar menor entre os poetas árcades, se der em relação à comparação quanto ao estilo poético em que o poeta dá início a um rompimento com a estilística conservadora classicista, Cascudo (1958) contesta a ideia de inferioridade trazendo a seguinte elucidação:

Quando Caldas Barbosa segue submissamente os moldes literários de Lisboa neoclássica e faz versos duros e frios estava juntando material para a fossa comum de todos os justos esquecimentos. Com a viola, cantando, era a voz sereneira, expressiva e legítima, o primeiro atrevimento, madrugada afoita, anunciando na Europa a lírica do povo do Brasil (CASCUDO, 1958, p. 30).

As afirmações de Cascudo (1958) podem ser enfatizadas com as palavras de Tinhorão (2004), que atestam que mesmo quando viria a se tornar o poeta Lereno, porém sendo ainda apenas um frustrado estudante em Coimbra, Domingos Caldas Barbosa já tinha seu sucesso destacado junto ao público devido aos seus "dotes de improvisador" e acrescenta que "o futuro poeta arcádico demonstrava àquele tempo clara consciência de superioridade de sua poética espontânea sobre a rigidez das forma consagradas do momento" (TINHORÃO, 2004, p. 50).

Prosseguindo as elucidações, o estudioso ressalta que é possível perceber a dualidade da voz poética em Domingos Caldas Barbosa afirmando que

Colocado na dupla posição de poeta cultor de formas neoclássicas, enquanto membro da Nova Arcádia, e de cantor-compositor de gêneros de música popular de origem brasileira (por ele mesmo introduzidos em Portugal) enquanto animador de assembleias, outeiros e saraus de salões lisboetas, Domingos Caldas Barbosa salvou-se para a posteridade por virtudes desta segunda arte, julgada menor (TINHORÃO, 2004, p. 107).

O autor declara ainda que essa "ambivalência" assumida pelo "poeta-modinheiro carioca" só seria considerada por historiadores de literatura em estudos mais recentes e que por isso

nomes de relevo da crítica e historiografia literária, como o professor Antonio Candido, deixavam de considerar o fato de que não havia apenas um, mas dois Domingos Caldas Barbosa a serem apreciados. Resultado: cometiam o equívoco de confundir os dois no mesmo julgamento crítico, para uma conclusão necessariamente desfavorável aos méritos do poeta-compositor (TINHORÃO, 2004, p. 108). 
Diante desta constatação, o estudioso retoma a declaração de Candido (2009) e levanta vários questionamentos como: "que 'patrícios mais bem dotados' seriam esses? Outros poetas brasileiros da época igualmente cantores e tocadores de viola, autores de 'letras' de melhor qualidade literária que as de Caldas?” (TINHORÃO, 2004, p. 109-110). Assim o crítico prossegue as indagações supondo:

Ora, se outros "patrícios mais bem dotados" a que o professor se refere eram Basílio da Gama, Cláudio Manuel da Costa, Tomás Antonio Gonzaga, Santa Rita Durão, Silva Alvarenga e Alvarenga Peixoto, todos autores de versos para serem lidos, e não cantados, como estabelecer a comparação? (TINHORÃO 2004, p. 110).

$\mathrm{O}$ autor reforça a necessidade de reconhecer "a existência dessa dupla linguagem praticada pelo Caldas Barbosa erudito enquanto árcade, e popular enquanto improvisador de cantigas e autor de modinhas e lundus" e afirma que

se ao contrário do que tem feito desde o século XIX historiadores e críticos literários, considerasse que houve estilisticamente não um, mas dois Domingos Caldas Barbosa — um cultivador de formas do neoclassicismo horaciano, outro fazedor-improvisador de versos para cantar - , a avaliação do poeta-compositor se tornaria muito mais fácil e justa (TINHORÃO, 2004, p. 110-111).

\section{Duas vozes em Lereno; voz alvinegra}

Até aqui, neste estudo, foi considerada a voz árcade de Lereno em comparação à voz de Glauceste sendo, na perspectiva das pressuposições sobre a literatura afro-brasileira, considerada como a voz branca por não haver presença de elementos indenitários da cultura afro-brasileira na poesia de estilo conservador neoclássico, mas é preciso considerar a outra voz do poeta da Viola de Lereno e ressaltar que já não é possível comparar a voz da linguagem erudita de Cláudio Manuel da Costa com a voz (outra) da linguagem popular de Domingos Caldas Barbosa, a voz do sujeito que revela sua identificação com a cultura negra, a voz que é encontrada nos lundus escritos sob influência do vocabulário das línguas africanas. Desta forma Lereno se sobressai aos poetas árcades pela dualidade alvinegra de linguagem poética, por ter inicialmente feito uso da linguagem predominantemente branca a fim de se constituir enquanto poeta e sujeito de voz que se faz ouvir e para que, posteriormente, a voz do poeta e sujeito negro pudesse ser audível num contexto social em que a voz do negro era calada porque este ocupava uma posição de inferioridade determinada pela sociedade colonial escravocrata.

Sobre a relevância fundamental do fenômeno da linguagem, atrelada às duas vozes no poeta Domingos Caldas Barbosa, torna-se pertinente evocar as declarações de Fanon (2008) em seu estudo envolvendo os negros antilhanos, intitulado Pele negra, máscaras brancas, mas especialmente na seguinte afirmação: 
É por esta razão que julgamos necessário este estudo, que pode nos fornecer um dos elementos de compreensão da dimensão para-o-outro do homem de cor. Uma vez que falar é existir absolutamente para o outro. O negro tem duas dimensões. Uma com seu semelhante e outra com o branco. Um negro comporta-se diferentemente com o branco e com outro negro. Não há dúvida de que esta cissiparidade é uma consequência direta da aventura colonial... (FANON, 2008, p. 33).

Baseando-se nestas "duas dimensões" que constituem o ser negro, o autor enfaticamente o caracteriza da seguinte forma:

Os pretos são comparação. Primeira verdade. Eles são comparação, ou seja, eles se preocupam constantemente com a autovalorização e com o ideal do ego. Cada vez que entram em contacto com um outro, advêm questões de valor, de mérito (FANON, 2008, p. 176).

Afirmação esta que corrobora com a consideração sobre o pressuposto de que o caminho encontrado por Domingos Caldas Barbosa diante de constante comparação, foi o caminho da resistência na busca por reconhecimento pelo inegável mérito e por isso o poeta se constitui tendo duas vozes distintas em Viola de Lereno.

Numa relação dialógica textual nesta reflexão sobre a constituição da voz de linguagem negra em Caldas Barbosa, evocar a voz de Conceição Evaristo (2009, p. 17) torna-se relevante quando a autora afirma que a escrita como expressão da voz negra é "marcada por uma subjetividade construída, experimentada, vivenciada a partir da condição de homens negros e de mulheres negras", mas que há uma contradição constatada nas seguintes palavras da autora:

Contudo, há estudiosos, leitores e mesmo escritores afrodescendentes que negam a existência de uma literatura afro-brasileira. Apegam-se à defesa de que a arte é universal, e mais do que isso, não consideram que a experiência das pessoas negras ou afrodescendentes possa instituir um modo próprio de produzir e de conceber um texto literário, com todas as suas implicações estéticas e ideológicas (EVARISTO, 2009, p. 17).

Apesar de sofrer zombaria racista dos intelectuais de sua época, ser satirizado por outros escritores como Bocage, que atribui a Lereno uma característica ofensiva animalizada quando usou a expressão "orangotango", ao assumir sua cor e ascendência, Caldas Barbosa é "um mulato que volta seu olhar para sua cor e escreve sobre isso", conforme as palavras de Camargo (2000 apud COSTA, 2018).

O crítico Luís da Câmara Cascudo (1958) também já havia ponderado sobre o uso da linguagem em Domingos Caldas Barbosa e assim descreve o poeta: "foi um 'cantador' autêntico, pondo na linguagem polida os acentos e as cores do seu país, de sua raça mestiça, do seu distante povo sentimental". E prossegue afirmando que o poeta "compreendeu sua posição 
e lugar" (CASCUDO, 1958, p. 22-23). Declaração esta que pode ser comprovada nos versos de um trocadilho em que Domingos Caldas Barbosa compõe ao se dirigir ao Pe. Antônio Pereira de Sousa Caldas (1762-1814) tratando-o como superior conforme o leitor pode constatar nas palavras dos versos que foram conservados:

Tu és Caldas, eu sou Caldas;

Tu és rico, eu sou pobre;

Tu és o Caldas de prata;

Eu sou o Caldas de cobre (CASCUDO, 1958, p. 23).

Ao se referir ao Pe. Sousa Caldas como sendo o "Caldas de prata" é possível inferir metaforicamente que a palavra prata pode representar a cor branca e ao referir-se a si mesmo como sendo "o Caldas de cobre" o poeta estivesse assumindo sua cor como mulato ou mestiço como alguns escritores preferem assim caracterizá-lo.

A estudiosa crítica de Domingos Caldas Barbosa Eduarda Rodrigues Costa (2018) introduz seu artigo confirmando o pertencimento do poeta à Nova Arcádia e seu nome arcádico, Lereno Selinuntino, declarando que o poeta "agitou a corte lisboeta com suas modinhas e lundus em pleno século XVIII" e reitera a afirmação sobre a necessidade de "salientar o quanto este poeta foi avançado em seu fazer artístico, buscando demonstrar o pertencimento ao Brasil e o vínculo com a tradição africana" e ainda que "a partir da compreensão do quanto o negro ou mestiço era estigmatizado naquele contexto pode-se reconhecer a ousadia de Domingos Caldas Barbosa em assumir sua etnicidade" (COSTA, 2018).

A ensaísta crítica afirma ainda que "levando-se em conta a consciência possível da época, pode-se considerar parte da obra do autor como pertencente à literatura afro-brasileira" (COSTA, 2018).

Da Viola de Lereno, o poema intitulado "Lundum” traz não somente as marcas identitárias ancestrais do poeta Domingos Caldas Barbosa, mas também elementos pertencentes à cultura afro-brasileira a exemplo das palavras "Nhanhazinha" e "iaiá".

Lundum

Eu tenho uma Nhanhazinha

A quem tiro o meu chapéu;

É tão bela tão galante,

Parece coisa do Céu.

$$
\begin{aligned}
& \text { Ai céu! } \\
& \text { Ela é minha iaiá, } \\
& \text { O seu moleque sou eu. }
\end{aligned}
$$


Eu tenho uma Nhanhazinha

Que eu não a posso entender;

Depois de me ver penar,

Só então diz que me quer.

Eu tenho uma Nhanhazinha

$A i$, etc.

A melhor que há nesta rua;

Não há dengue como o seu,

Nem chulice como a sua.

Eu tenho uma Nhanhazinha

Ai, etc.

Muito guapa muito rica;

O ser formosa me agrada,

$\mathrm{O}$ ser ingrata me pica.

Eu tenho uma Nhanhazinha

$A i$, etc.

De quem sou sempre moleque;

Ela vê-me estar ardendo,

$\mathrm{E}$ não me abana com o leque.

Eu tenho uma Nhanhazinha

Ai, etc.

Por quem chora o coração;

E tanto chorei por ela,

Que fiquei sendo chorão (BARBOSA, 1944, p. 27-29).

No lundu "Lundum", o eu lírico canta à amada referindo-se a ela com o diminutivo de nhanhá, "Nhanhazinha", que segundo nota de Cascudo (1958, p. 81) esta é uma "denominação dada pelos escravos às sinhá-moças, filha dos amos". Expressão também conhecida como iaiá e que na linguagem do poeta caracteriza as "marcas da oralidade que o poeta herdara de seu pertencimento étnico racial e na sua convivência nos subúrbios da jovem colônia" (OLIVEIRA, 2018).

Ao identificar-se como "seu moleque", o poeta não apenas se coloca numa posição de cativo da amada, mas também evoca tratamento afetivo, já que segundo nota de Cascudo (1958, p. 81), esta expressão "era título carinhoso, de acentuação amorosa ou cativante, muito comum no Brasil das primeiras décadas do séc. XIX" e que não apenas foi usado para se referir aos escravos mais jovens, mas "o Imperador D. Pedro I dizia-se moleque da Marquesa de Santos, Domitila de Canto e Castro".

Há ainda no poema palavras como "dengue" e "chulice", as quais Tinhorão (2004, p. 21) caracteriza como sendo expressões "com requintes de maliciosa observação psicológica escondida em linguagem popular"; segundo o estudioso, estas expressões também podem ser sinônimas de "meneios da nhanhá que afetavam promessas de carícias" das quais o autor compara tanto com a doçura do "quindim", quanto com a ação que queima a "malagueta", 
expressões estas de origem da culinária africana, que Caldas Barbosa cita nos versos do poema "Lundum de cantigas vagas".

\section{Lundum de cantigas vagas}

Xarapim, eu bem estava

Alegre nest'aleluia,

Mas para fazer me triste

Veio amor dar-me na cuia.

Não sabe, meu Xarapim

O que amor me faz passar,

Anda por dentro de mim

De noite, e dia a ralar.

Meu Xarapim, já não posso

Aturar mais tanta arenga,

$\mathrm{O}$ meu gênio deu à casca

Metido nesta moenga.

Amor comigo é tirano,

Mostra-me um modo bem cru;

Tem-me mexido as entranhas

$\mathrm{Qu}$ 'estou todo feito angu.

Se visse o meu coração

Por força havia ter dó,

Pois que Amor o tem posto

Mais mole que quingombó.

Tem nhanhã certo nhonhô,

Não temo que me desbanque;

Porque eu sou calda de açúcar

E ele apenas mel de tanque.

Nhanhá cheia de cholices

Que tantos quindins afeta,

Queima tanto a quem a adora

Como queima a malagueta (BARBOSA, 1944, p.15).

Além do uso das várias palavras do universo afro-brasileiro, como xarapim, cuia, arenga, moenga, nhonhô, e novamente a expressão nhanhá já usada no poema "Lundum", no poema "Lundum de cantigas novas", o poeta também faz uso do vocabulário da culinária afro-brasileira, extraído da linguagem popular. São usadas expressões como angu, quingombó, quindins, malagueta, além de outras expressões em que são visíveis as marcas da oralidade que diferencia Caldas Barbosa dos seus contemporâneos.

O estudioso Tinhorão (2004) faz uma análise sobre as expressões afro-brasileiras usadas por Lereno em "Lundum de cantigas novas" com as seguintes considerações: 
Além de dirigir-se a um Xarapim — que tanto podia ser algum homônimo (xará), quanto um bom companheiro (tal como se usa hoje na expressão "meu chapa", tão indicativo de possível apócope de xarapim) —, o poeta comprazia-se em alinhar neologismos e expressões coloquiais normalmente só compreensíveis no Brasil. "Veio Amor dar-me na cuia", no sentido de ocupar-lhe o pensamento, porque na gíria brasileira cabeça é cuia (quando não é coco). Ao dizer "não aturar mais tanta arenga", usava a palavra própria para discurso cansativo, ou lengalenga, no sentido de intriga, falatório ou mexerico. E como é vítima de tais murmurações sente a cabeça como que esmagada numa moenda, escrevia que seu "gênio deu à casca/Metido nesta moenga" (moenda por moenga, variante ainda não registrada em dicionários) (TINHORÃO, 2004, p. 120-121).

No "Lundum de cantigas novas", Lereno não apenas reuniu expressões corriqueiras, quer expressas em forma do equivalente a pronome de tratamento, quer simples vocabulário nominativo, mas deixa perceptível a vazão do lirismo amoroso misturado ao sabor de elementos da culinária afro-brasileira, ao que as elucidações nas análises do estudioso se tornam explicações de grande relevância quando afirma que

Tal incômoda sensação provocada pelo amor que o ralava ("Anda por dentro de mim/ De noite e dia a ralar"), sentia-a até mesmo nas entranhas, tão mexidas — dizia "Qu'estou todo feito de angu" - a massa de farinha que ganha consistência escaldada ao fogo. Quanto ao coração, sujeito a tal sentimento, sentia-o Caldas Barbosa "Mais mole que quimbombó", ou seja, do que quiabo depois de cozido. Muito brasileiramente, o poeta denomina ainda nas "cantigas vagas" (ou quadras soltas) de seu lundu, a rapariga de nhanhã, e seu rapaz de nhónhó (brasileiríssimos derivados de expressão de tratamento respeitoso que os africanos davam aos brancos, depois simplificados nas formas de iaiá e ioiô) (TINHORÃO, 2004, p. 121).

Ao retomar o poema "Retratos de minha linda pastora", é concebível perceber a presença da dualidade da voz alvinegra de Domingos Caldas Barbosa, uma vez que, nas sete estrofes iniciais, o poeta pastor dá vazão ao lirismo amoroso cantando o amor à pastora amada se valendo de elementos bucólicos característicos do Arcadismo e neste aspecto se assemelha aos poetas árcades contemporâneos, como Cláudio Manuel da Costa, especialmente no que se refere aos elementos da natureza com aspectos semelhantes e que aproximam Lereno e Glauceste. No entanto, a partir da oitava estrofe, Lereno começa a assumir a voz que o diferencia de Glauceste porque assume sua identidade mestiça quando passa a louvar a beleza "morena" da mulher afrobrasileira em contraposição à beleza das musas de claros olhos e cabelos à moda camoniana da qual o Arcadismo brasileiro recebe como legado e que Lereno "faz remissão a uma estética feminina diversa da escolhida como padrão daquela época” conforme afirma Costa (2018).

Engraçada por morena,

Tem redonda e face bela;

Não há boca como aquela, 
Nem melhor, nem mais pequena.

$[\ldots]$

São as mãos também morenas

As que à graça aumento dão;

As validas de Amor são

Podem tanto tão pequenas (BARBOSA, 1798, p. 26-27).

Diante das leituras e reflexões sobre a poesia de Domingos Caldas Barbosa, considerada por vários autores da crítica literária como sendo árcade ou neoclássica, é perceptível que não se pode negar tal afirmativa, já que o autor fazia parte da Arcádia de Roma, era requisitado nos salões da nobreza e sua voz erudita se assemelha à voz dos árcades, seus contemporâneos, como Cláudio Manuel da Costa. No entanto, além da voz poética arcádica de Lereno, é preciso considerar também a voz que assume sua identidade negra, a "voz de um audacioso inovador a quem não bastou utilizar a temática e o estilo clássico" (COSTA, 2018). A poesia de Domingos Caldas Barbosa também é notoriamente de base popular, pois ao compor sua lírica Lereno transpunha para suas linhas e formas ritmos afro-brasileiros como a modinha e o lundu que trazem consigo marcas da oralidade africana. Esta dualidade de voz alvinegra do poeta pastor Lereno ao mesmo tempo que o aproxima de Glauceste na erudição, temática e estética, o distingue na inovação do uso do lirismo da voz afro-brasileira.

\section{Referências}

BARBOSA, Domingos Caldas. Viola de Lereno. Lisboa: Officina Nunesiana, 1798.

. Viola de Lereno. 2. ed. Rio de Janeiro: Imprensa Nacional, 1944.

CANDIDO. Antonio. Os poetas da inconfidência. IX Anuário do Museu da Inconfidência. Ouro Preto: Ministério da Educação e Cultura, 1993. p. 130-7.

. Formação da literatura brasileira: momentos decisivos, 1750-1880. 12. ed. São Paulo/ Rio de Janeiro: FAPESP/Ouro sobre Azul, 2009.

CASCUDO, Luís da Câmara. Caldas Barbosa: poesia. Rio de Janeiro: Agir, 1958.

COSTA, Eduarda Rodrigues. Pertencimento étnico e transgressão em Viola de Lereno, de Domingos Caldas Barbosa. Literafro. 2018. Versão online. Disponível em: http://www. letras.ufmg.br/literafro/autores/28-critica-de-autores-masculinos/223pertencimento-etnico-etransgressao-em-viola-de-lereno-de-domingos-caldas-barbosa-critica. Acesso em: 5 jul. 2019.

EVARISTO, Conceição. Literatura negra: uma poética de nossa afro-brasilidade, Scripta, Belo Horizonte, v. 13, n. 25, p. 17-31, dez. 2009. Disponível em: http://periodicos.pucminas.br/ index.php/scripta/article/view/4365/4510. Acesso em: 12 ago. 2019.

FANON, Frantz. Pele negra, máscaras brancas. Tradução Renato da Silveira. Salvador: EDUFBA, 2008. 
OLIVEIRA, Laura M. A. A africanidade na obra Viola de Lereno de Domingos Caldas Barbosa. Literafro. 2018. Versão online. Disponível em: http://www.letras.ufmg.br/literafro/autores/28critica-de-autores-masculinos/1114-a-africanidade-na-obra-viola-de-lereno-de-domingoscaldas-barbosa. Acesso em: 5 jul. 2019.

PROENÇA FILHO, D. (org.). A poesia dos inconfidentes: poesia completa de Cláudio Manuel da Costa, Tomás Antônio Gonzaga e Alvarenga Peixoto. Artigos, ensaios e notas de Melânia Silva de Aguiar et al. Rio de Janeiro: Nova Aguilar, 1996.

SAWAYA, Luiza. Domingos Caldas Barbosa, herdeiro de Horácio: poemas no Almanak das Musas: estudo crítico. Lisboa: Esfera do Caos Editores, 2015.

TINHORÃO, J. R. Domingos Caldas Barbosa: o poeta da viola, da modinha e do lundu (17401800). São Paulo: Editora 34, 2004.

\section{Minicurrículo}

Tânia de Assis Silva é pesquisadora no Programa de Pós-Graduação em Estudos Literários (PGELi) da Universidade Estadual Paulista “Júlio de Mesquita Filho" (Unesp), onde desenvolve a pesquisa que tem como base um estudo comparativo entre os poetas Camões e Cláudio Manuel da Costa pelo viés do bucolismo clássico que ressoa na poesia árcade, neoclássica brasileira. 